\title{
A train bearing fault detection and diagnosis using acoustic emission
}

\author{
Tonphong Kaewkongka*
}

Department of Physics, Faculty of Science, Chulalongkorn University, Patumwan, Bangkok 10330, Thailand

\begin{tabular}{l}
\hline A R T I C L E I N F O \\
\hline Article history: \\
Received 6 September, 2015 \\
Accepted 9 December 2015 \\
Available online \\
9 December 2015 \\
\hline Keywords: \\
Acoustic emission \\
Bearing \\
Train \\
Detection \\
Diagnosis \\
\hline
\end{tabular}

A B S T R A C T

\begin{abstract}
This paper provides a method of acoustic emission (AE) technique to detect a train bearing fault of tapered bearing unit (TBU). An approach is to utilize acoustic emission signals which were captured from piezoelectric transducer and processed using Fourier transform. The transformed signals may contain unique characteristic features relating to the various types of bearing faults. The experiments on different operating conditions were investigated and they corresponded to (a) a normal bearing and (b) outer race defect bearing. The result is promising for faulty bearing identification and discrimination between different bearing conditions.
\end{abstract}

(C) 2016 Growing Science Ltd. All rights reserved.

\section{Introduction}

The safe and reliable operation of a railroad transportation system is dependent upon the integrity of the rotor-dynamic mechanism of the vehicles traveling over the rails. It is necessary to monitor a condition of train bearings to determine if a degree of wear on the bearing indicates that the bearings need to be closely inspected and repaired or even replaced. An undetected faulty bearing may collapse and causes the train derailed, which is extremely disastrous and causes great economic loss. Sometimes it even causes health and safety consequences. A reliable condition monitoring system is therefore highly desirable since it will alleviate the cost of these consequences and enhance the overall equipment effectiveness. For bearing maintenance, two methods have been used, namely the statistical bearing life estimation and the bearing condition monitoring and diagnostics (Shiroishi et al., 1997). The first method relies on a model of the bearing survival probability in terms of the dynamic load rating and the equivalent load to give a prediction of the fatigue life of a bearing (Pachaud et al., 1997; Li et al., 1999). However, since operating conditions can vary significantly from one machine to another, the prediction based on the assumption of normal duty on a bearing can be in serious error. The second method, in theory, is superior to the first one if the signals monitored have useful features that can

\footnotetext{
* Corresponding author

E-mail addresses: tonphong.k@chula.ac.th (T. Kaewkongka) 
reliably indicate a potential failure well ahead of the occurrence of the corresponding functional failure (Qu et al., 1989; Choe et al., 1997; Holroyd, 2002; Ying \& Rong, 2013).

In this paper, a frequency-domain technique, namely the Fast Fourier Transform (FFT) is assessed in terms of its ability to discriminate between different types of signals that had transient features in them. These signals were collected from different bearing conditions. The objective of this research is to demonstrate that a condition-based monitoring using acoustic emission (AE) can provide not only timely detection of low speed bearing but also the fault identification so that maintenance or replacement can be performed prior to the loss of safety function. Therefore, the use of acoustic emission method has been proposed to use for low speed machineries monitoring instead of those conventional method.

\section{The proposed approach}

Fig. 1 shows a block diagram of the proposed bearing condition monitoring procedure. The acquired AE signals are first filtered and amplified to remove noise and then processed in order to obtain AE signal. Then, the Fast Fourier Transform (FFT) was used to produce its frequency domain pattern. The frequency domain has a horizontal axis representing frequency and a vertical axis representing the intensity of the frequency component.

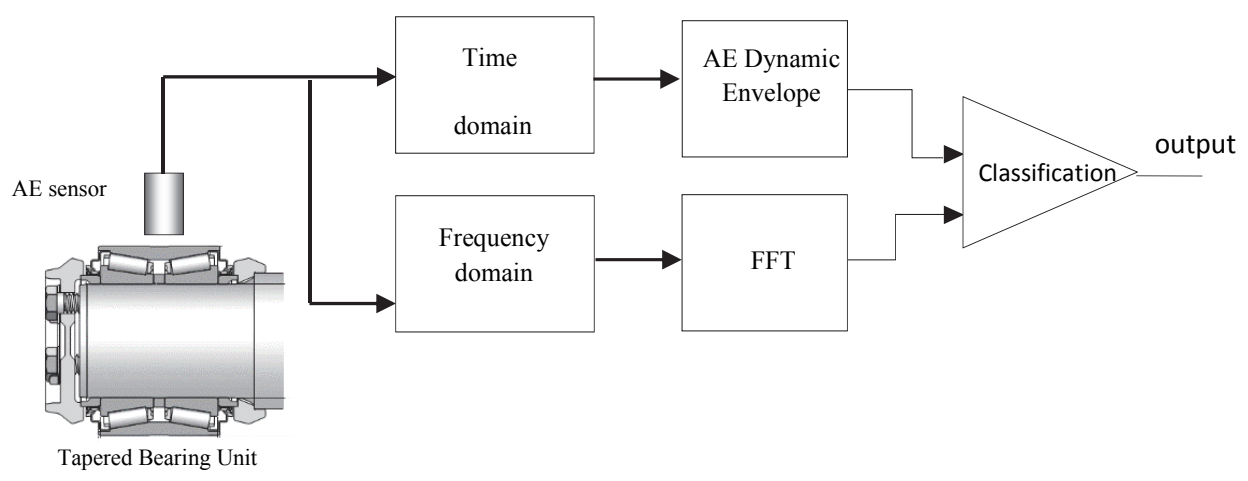

Fig. 1. The proposed train bearing fault detection block diagram.

In order to use such pre-processed parameter, the dynamic envelope of the AE signal can be obtained from AE sensor (HOLROYD INSTRUMENTS, UK) as shown in Fig. 2. The AE sensor is resonated at $100 \mathrm{kHz}$, which can provides many opportunities for diagnosing the nature of faults. The time dependence of the AE signal can reveal the occurrence and timing of subtle actions within machineries.

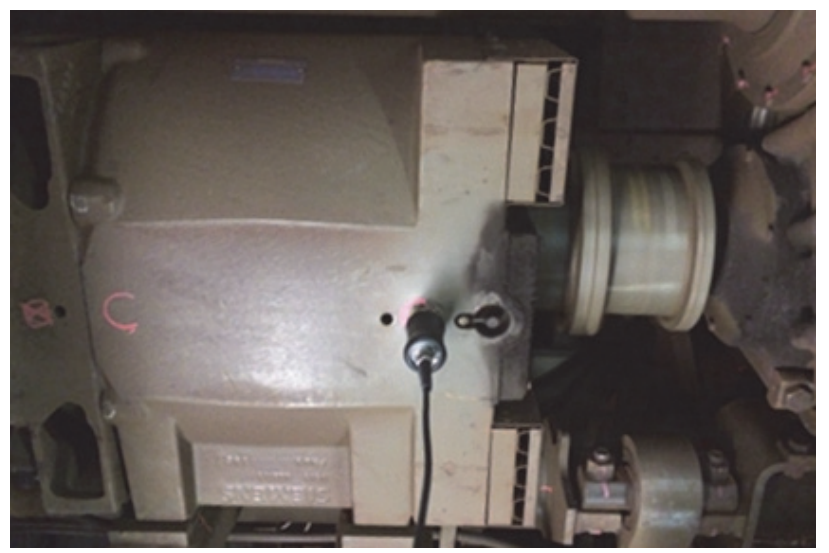

Fig. 2. Acoustic Emission (AE) sensor (HOLROYD INSTRUMENTS, UK) 
The AE dynamic envelope is used in this study because it contains significant amount of information about the AE bursts, which are generally characterized by transient in magnitude of the AE signal followed by a much gradual decay (Holroyd, 2002). It can be described mathematically as

$$
v(t)=v_{O} e^{(-\beta t)} \sin (\omega t) .
$$

For the above equation to be valid, the signal $v(t)$ is the instantaneous voltage of the AE waveform. The $\mathrm{v}_{\mathrm{o}}$ is the theoretical peak voltage of the burst waveform at initial time and $\beta$ is the attenuation coefficient. To find the $\mathrm{dB}_{\mathrm{AE}}$ from the time domain signal, one can derive from the output voltage compared to the reference voltage, 1 microvolt.

$$
d B_{A E}=20 \log \frac{V_{\text {out }}}{V_{\text {ref }}} .
$$

To identify the roto-dynamic faults of rotating machineries, the Fast Fourier Transform (FFT) employed in different papers (i.e. Choe et al., 1997; Paya \& Esat 1997; Safizadeh et al., 2000) is used in this study. The Fourier transform of a signal $x(t)$ is defined as:

$$
F[x(t)]=X(f)=\frac{1}{2 \pi} \int_{-\infty}^{+\infty} x(t) e^{-j 2 \pi f t} d t .
$$

For Equation to be valid, the signal $x(t)$ being transformed must be stationary, which means that its amplitude distribution does not depend on absolute time. In other words, the moments of the distribution - for example, mean, variance, etc. are stationary.

\section{Experimental set-up for the proposed bearing fault detection using AE method}

The experimental set up was performed on the actual train bearing operating conditions of the electric train as shown in Fig. 3. Its schematic diagram of the test rig is also shown in Fig. 4. The spindle is driven by a variable speed motor running at $90 \mathrm{rpm}$. The two bearings were TBU (tapered roller bearing unit), with the inner and outer diameter of $130 \times 230 \mathrm{~mm}$, which is based on a sealed and factory lubricated bearing unit that is ready to mount. They were mounted in bearing housings which in turn were attached to a base plate. The test rig provides facilities to produce the different machine operating conditions characterized by:

1. the rotating shaft dynamically balanced (referred to as 'normal condition'),

2. the rotating shaft dynamically balanced in with unknown condition at that time (referred to as 'defective bearing' as found out later after replaced)

Acoustic emission signal at the bearing was measured using AE sensor which is manufactured by Holroyd Instruments, UK (on top of both end and non-drive end housing). The AE sensor has resonance frequency at $100 \mathrm{kHz}$. The acquired AE signals, having been band-pass filtered at $20 \mathrm{kHz}$ to $500 \mathrm{MHz}$ for noise-removal and amplified to $60 \mathrm{~dB}$, were sampled into a data acquisition card. Measurements were obtained from different machine conditions: normal and defective bearings. For each condition, ten signals were collected as for data processing.

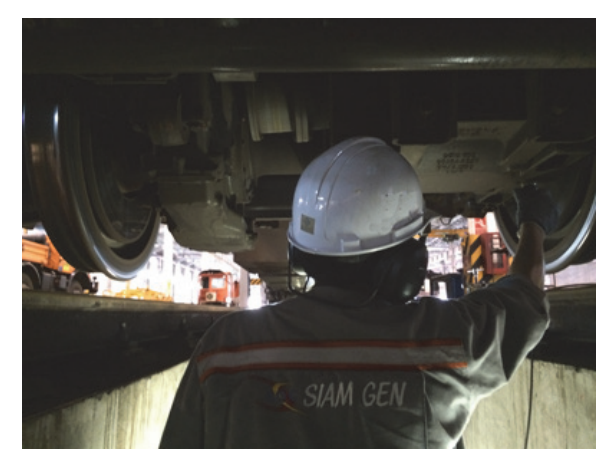

Fig. 3. Experimental set up for TBU bearing fault detection using $\mathrm{AE}$

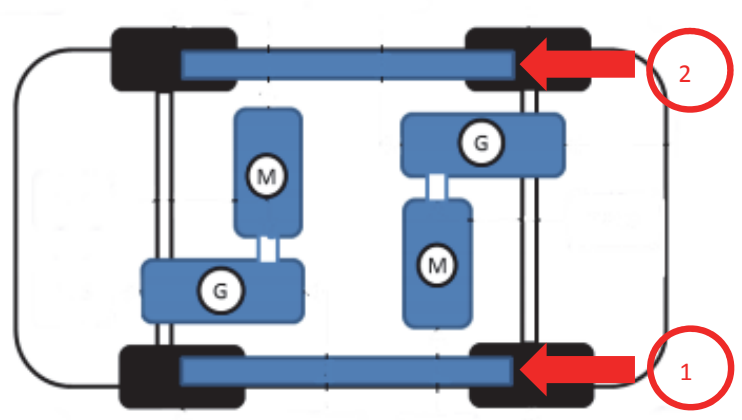

Fig. 4. Testing of TBU bearing position schematic diagram 


\section{Experimental results and discussion}

Measurements were obtained from different machine conditions: normal and defective bearings. Table 1 shows the signal measured on bearing housing from different operating conditions. In the experiment, the AE dynamic envelope collected from a normal bearing yields mean of logarithm intensity about $10.4 \mathrm{~dB}$ whilst the intensity obtained from the defective bearing is about $21.2 \mathrm{~dB}$.

As can be seen from the result of the measurement, the $\mathrm{dB}_{\mathrm{AE}}$ from the defective bearing is greater than one obtained from the normal bearing by $10.8 \mathrm{~dB}$ which is approximately 3.5 times greater than the normal condition bearing. With machine fault condition result in greater energy release rates they produce higher continuous signal levels (such continuous signals result from the overlapping of many small transient signals).

Table 1. Results of measured $\mathrm{dB}_{\mathrm{AE}}$ from the time domain of the TBU bearings

\begin{tabular}{lcc}
\hline Bearing condition & \multicolumn{3}{c}{$\mathrm{dB}_{\mathrm{AE}}$} \\
\hline No\# & Normal & Defective \\
\hline 1 & 11 & 21 \\
2 & 11 & 22 \\
3 & 11 & 21 \\
4 & 10 & 20 \\
5 & 11 & 22 \\
6 & 9 & 23 \\
7 & 10 & 21 \\
8 & 11 & 21 \\
9 & 10 & 20 \\
10 & 10 & 21 \\
\hline Average & $\mathbf{1 0 . 4}$ & $\mathbf{2 1 . 2}$ \\
\hline
\end{tabular}

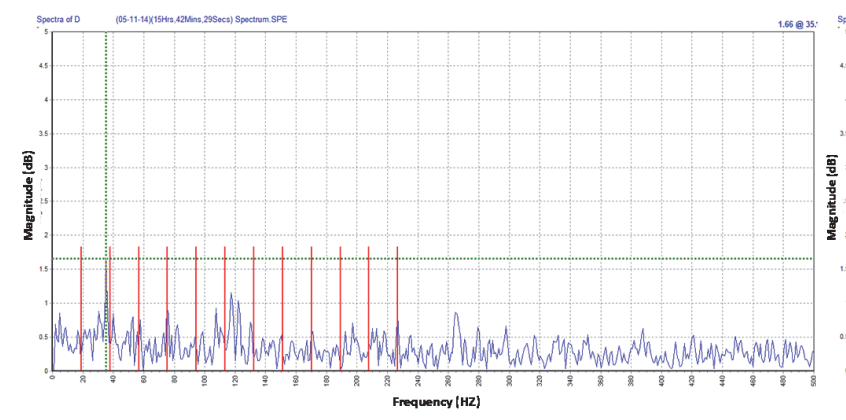

(a)

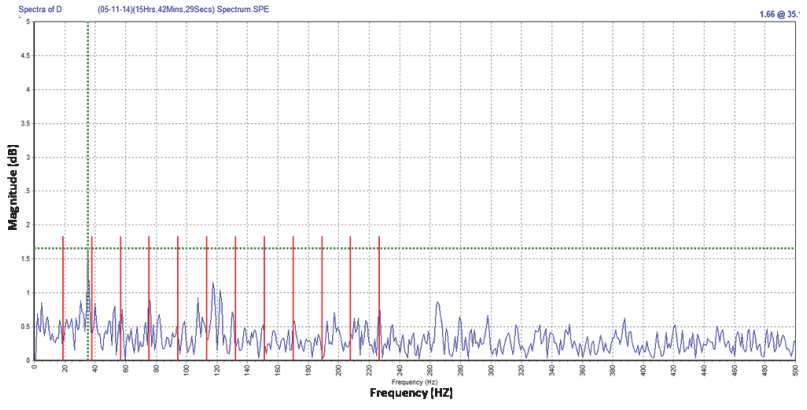

(b)

Fig. 5. Results of spectrum from (a) normal bearing and (b) defective bearing.

Fig. 5 shows the outcome of the spectrum collected from a) normal and b) defective bearings. The normal bearing spectrum does not show any indication of the bearing defect frequency. In contrast, the defective bearing spectrum indicates the high peak at frequency of $2 \times$ of its outer race defect frequency $(18.9 \mathrm{~Hz} \times 2=37.8 \mathrm{~Hz})$. This yields the diagnostics capability of the proposed AE method to reveal its faulty condition of the train bearing. Other methods such as source location (Scholey et al., 2009) can also be used to eliminate unwanted AE sources for better predicting the development of damage mechanisms in the faulty devices like Bearings. 

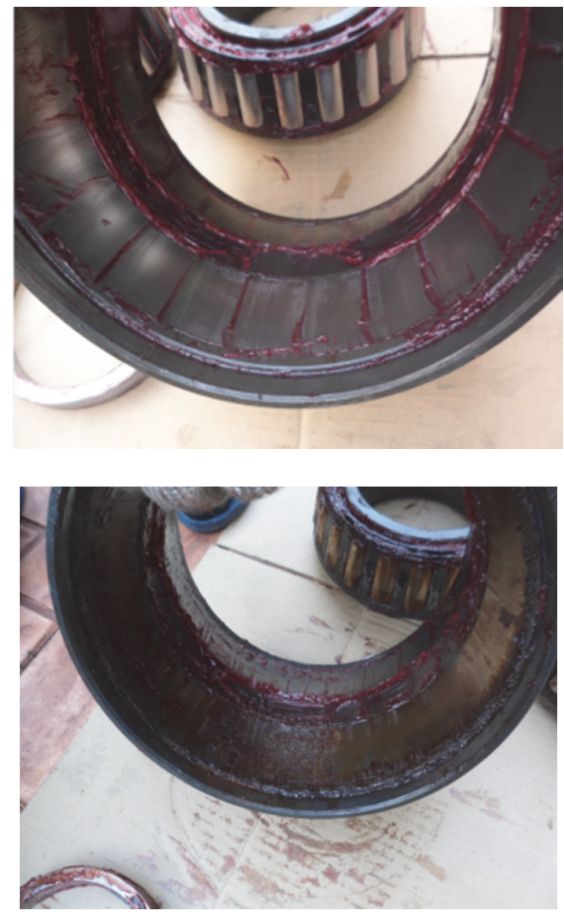

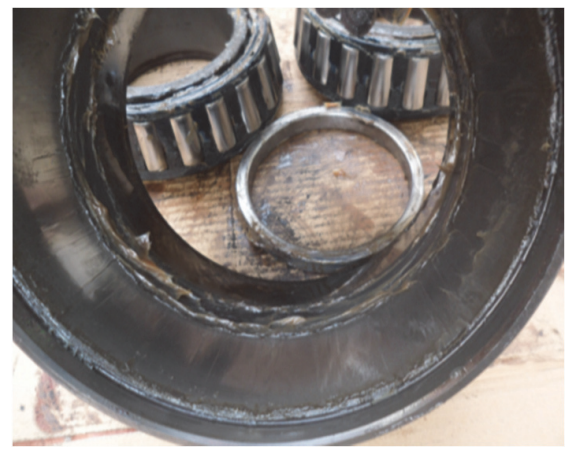

(a)

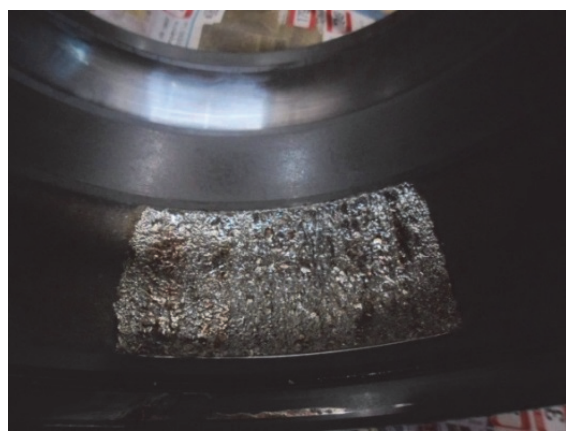

(b)

Fig. 6. Results of before and after cleaning of (a) normal bearing and (b) defective bearing

To verify the experimental results, both bearing were taken apart from the TBU tapered bearing unit. Fig. 6 shows the actual condition of the bearing of before- and after- cleaning of the bearing. Fig. 6 (a) shows the condition of the normal bearing. There is no significant damage on the raceway of the bearing. Fig. 6 (b) shows the condition of the defective bearing at the outer race. It has experienced the excessive load on the raceway which can be found from its spectrum (at 2x of outer race defect frequency). It is obvious that the proposed method can be used to detect and diagnose the train bearing operating condition.

The experiments indicated that both AE dynamic envelope and its FFT spectrum of acoustic emission signals from different roto-dynamic machine conditions (i.e. normal and defective bearings) produced distinct pattern of signals that could be discriminated by operator. The recognition rate achieved with the limited test sets was promising. As a conclusion, the result of this paper demonstrates the validity of $\mathrm{AE}$ technique for identifying faulty train bearings at different working conditions

\section{Acknowledgements}

The author gratefully acknowledges the support of the Department of Physics, Faculty of Science, Chulalongkorn University, Siam Gen Co., Ltd. (Thailand) and Tetsugen Jitsugyo Ltd (Japan) for their advice and technical support.

\section{References}

Choe, H. C., Wan, Y., \& Chan, A. K. (1997, April). Neural pattern identification of railroad wheelbearing faults from audible acoustic signals: Comparison of FFT, CWT, and DWT features. In AeroSense'$^{\prime} 7$ (pp. 480-496). International Society for Optics and Photonics.

Holroyd, T. J. (2002). Acoustic emission sensors for OEM applications. Engineering science and education journal, 11(1), 29-35. 
Li, Y. S. C. T. S., Billington, S., Zhang, C., Kurfess, T., Danyluk, S., \& Liang, S. (1999). Adaptive prognostics for rolling element bearing condition. Mechanical systems and signal processing, 13(1), 103-113.

Pachaud, C., Salvetat, R., \& Fray, C. (1997). Crest factor and kurtosis contributions to identify defects inducing periodical impulsive forces. Mechanical Systems and Signal Processing, 11(6), 903-916.

Paya, B. A., Esat, I. I., \& Badi, M. N. M. (1997). Artificial neural network based fault diagnostics of rotating machinery using wavelet transforms as a preprocessor. Mechanical systems and signal processing, 11(5), 751-765.

Qu, L., Liu, X., Peyronne, G., \& Chen, Y. (1989). The holospectrum: a new method for rotor surveillance and diagnosis. Mechanical Systems and Signal Processing, 3(3), 255-267.

Safizadeh, M. S., Lakis, A. A., \& Thomas, M. (1900). Using short-time Fourier transforms in machinery fault diagnosis. COMADEM, International Journal, 3(1), 5-16.

Scholey, J. J., Wilcox, P. D., Wisnom, M. R., Friswell, M. I., Pavier, M., \& Aliha, M. R. (2009). A generic technique for acoustic emission source location. $J$ Acoust Emis, 27, 291-298.

Shiroishi, J. Y. S. T., Li, Y., Liang, S., Kurfess, T., \& Danyluk, S. (1997). Bearing condition diagnostics via vibration and acoustic emission measurements. Mechanical systems and signal processing, 11(5), 693-705.

Wang, Y., \& Wu, Z. R. (2013, October). A Train Hot Bearing Detection System Based on Infrared Array Sensor. In Applied Mechanics and Materials (Vol. 347, pp. 672-676). 